\title{
Medical Students' Knowledge of the Cause-of-Death Certification: A Descriptive, Cross-Sectional Study from Saudi Arabia
}

\section{Mohammed Madadin (D)}

Department of Pathology, College of Medicine, King Fahd Hospital of the University, Imam Abdulrahman Bin Faisal University, Dammam, Saudi Arabia
Correspondence: Mohammed Madadin Department of Pathology, College of Medicine, King Fahd Hospital of the University, Imam Abdulrahman Bin Faisal University, Dammam, 342 II, Saudi Arabia Tel +966 I3 3333766; +966504997673 Fax +966 I3 3330333

Email Mmadadin@iau.edu.sa
Background: The medical certificate of cause-of-death is an important document of medicolegal significance. Errors in the completion of the death certificate by doctors are not uncommon. Therefore, it is important for medical students, the future doctors, to be trained in completing the medical certificate of cause-of-death. This study aimed to investigate the understanding of final-year medical students of the cause-of-death certification and to assess their ability to complete the cause-of-death statement.

Material and Methods: The final-year medical students of Imam Abdulrahman Bin Faisal University, of the academic year 2020-21 formed the cohort of medical students that participated in the current descriptive, cross-sectional study wherein a self-administered online questionnaire was used.

Results: A total of 174 students provided complete responses. The immediate cause of death in the given case scenario was answered correctly by $107(61.5 \%)$ of the students. The underlying cause of death was answered correctly by only $20(11.5 \%)$ students. It was apparent that the chain of events leading to death in the given case scenario was wrongly understood by the majority of the students. Nonetheless, the other significant condition contributing to death was answered correctly by $151(86.8 \%)$ students. Other errors included the use of abbreviations, mention of the mechanism of death as a cause of death, mention of clinical features or irrelevant causes of death and mention of the incorrect time interval between the onset of a cause of death and death.

Conclusion: The current study found that the overall performance of final-year medical students was reasonably good except for the fact that most misunderstood the underlying cause of death in the given case scenario. The majority of the students had attended a tutorial on medical certification of cause-of-death before participating in the current study, which suggests that continuous training might be required.

Keywords: death certification, cause of death, medical student, future doctor, death certificate

\section{Introduction}

The medical certificate of cause-of-death is an important document of medicolegal significance that a doctor certifies following the death of his/her patient. This document serves as the permanent record of the death of a person and includes vital information pertaining to the demographics of the deceased and the cause-of-death statement. ${ }^{1,2}$

Errors in the completion of the medical certificate of cause-of-death by doctors are not uncommon globally. ${ }^{3,4}$ A study conducted in Nepal reported errors in 79\% of death certificates. ${ }^{5}$ In a study conducted in Greece, Filippatos et al reported 
inaccuracies in death certificates that included the mention of the mechanism of death, improper sequencing of causes of death, and the mention of an irrelevant cause of death in $5.8 \%, 16.8 \%$, and $31.2 \%$ of the death certificates, respectively. ${ }^{6}$ A Saudi Arabian study reported an incorrect cause of death in all the 1729 death certificates that were evaluated. $^{7}$

Writing an erroneous underlying cause of death substantially impacts the cause-of-death statistics. ${ }^{8}$ Therefore, writing the cause-of-death statement without errors is essential to build accurate mortality data that is important to measure the effectiveness of various mortality reduction programs. ${ }^{9}$

It is reported that resident physicians or junior physicians, in particular, are often known to make errors in completing the death certificate and a significant proportion of them are known not to have received prior formal training in drafting death certificates. ${ }^{10}$ For instance, a study conducted in Thailand reported inaccuracies in death certificates completed by first-year general practitioners and only $28 \%$ of them had experience in independently completing death certificates as medical students. ${ }^{11}$ Therefore, it is important for medical students, the future doctors, to be trained in completing the medical certificate of cause-of-death as this document primarily serves various important purposes for the legal heirs of the deceased and secondly is a vital source for mortality statistics.

The objective of the current study was to investigate the understanding of final-year medical students on the cause-of-death certification and to assess their ability to complete the cause-of-death statement.

\section{Materials and Methods Design}

A descriptive, cross-sectional study was conducted to assess medical students' knowledge of completing the medical certification of the cause-of-death by using an online questionnaire.

\section{Sample}

The final-year medical students of Imam Abdulrahman Bin Faisal University formed the cohort of medical students that participated in the current online questionnaire-based study. The total number of final-year medical students for the academic year 2020-2021 was 274, including 134 males and 140 females. Twenty of these students completed the pre-test of the questionnaire as a part of the pilot study.
A print format of the questionnaire was used for the pilot study that was conducted a month before the actual study. These 20 students were not invited to participate in the ultimate study, leaving the potential maximum number of students eligible to participate in the study at 254 . Accordingly, a minimum sample size of 153 participants was estimated using a confidence level of $95 \%$ and a $5 \%$ margin of error. All the eligible participants were informed about the purpose of the current study.

\section{Setting}

A two-hour tutorial on medical certification of the cause-of -death was conducted for the final-year medical students as a part of the medical curriculum at the beginning of the first semester of the final year. Data for the current study was obtained from the final-year medical students of the aforementioned university in Saudi Arabia at the end of the first semester of the final year.

\section{Instrument}

The questionnaire was drafted in English and adopted from previous studies and based on a review of related literature. ${ }^{12,13}$ The content of the questionnaire was validated by three experts in the field with sound knowledge of research methodology. The questionnaire was pre-tested on a convenience sample of 20 students to ensure clarity, and then finalized accordingly based on their feedback.

The questionnaire included an introduction to the current study with the objective of the study stated, a section on medical students' consent to participate, a section on demographic characteristics of the participants, and a section testing their knowledge on completion of the cause-of-death statement, including responses to a relevant case scenario (Table 1) and 10 independent statements/questions on the cause-of-death certification.

\section{Procedure}

A self-administered questionnaire was distributed to the eligible final-year medical students of the aforementioned university using an online platform. There were no incentives offered for participation in the current study, and participation was on a voluntary basis. The consent was specified and included as the first section in the questionnaire.

\section{Analysis}

IBM SPSS Statistics 27 (IBM Corp. in Armonk, NY) was used for statistical analysis of the data. 
Table I Case Scenario and the Correct Cause-of-Death Statement

\begin{tabular}{|c|c|c|}
\hline \multicolumn{3}{|c|}{ Cause-of-Death Statement } \\
\hline \multicolumn{2}{|l|}{ Cause of Death } & $\begin{array}{c}\text { Approximate Interval Between Onset } \\
\text { and Death }\end{array}$ \\
\hline \multirow{2}{*}{$\begin{array}{l}\text { I. Disease or condition directly leading to death } \\
\text { Antecedent causes (morbid conditions, if any, giving rise to the } \\
\text { above cause) }\end{array}$} & (a)Pulmonary embolism & 5 hours \\
\hline & $\begin{array}{l}\text { (b) Deep vein thrombosis of the } \\
\text { right leg } \\
\text { (c) Factor V Leiden thrombophilia } \\
\text { (d) } \\
\text { (e) }\end{array}$ & $\begin{array}{l}10 \text { days } \\
5 \text { years } \\
\end{array}$ \\
\hline II. Other significant conditions contributing to the death & Bronchial asthma & 15 years \\
\hline
\end{tabular}

Notes: Noorah, aged 29, presented to the emergency department of a hospital with severe breathlessness of 4 hours duration. Ten days prior to her presentation to the emergency department, she had suffered from pain and swelling of the calf region of the right lower limb and a diagnosis of deep vein thrombosis (DVT) of the right leg was made by her family physician. Other significant past history revealed that she was diagnosed with factor $V$ Leiden thrombophilia in 2015 . She is a known asthmatic for the last 15 years. One hour after her present admission to the hospital, she suffered a cardiac arrest and was pronounced dead after a failed resuscitation effort.

\section{Ethical Approval}

The current study was conducted after obtaining approval from the Institutional Review Board (IRB) of the aforementioned university. Identifiable information of the participants was not obtained.

\section{Results}

A total of 174 students provided complete responses, of whom $115(66.09 \%)$ were female and $59(43.91 \%)$ were male. Of the respondents, $170(97.7 \%)$ attended the twohour tutorial of medical certification of the cause-of-death, whereas four $(2.3 \%)$ students did not attend.
Table 2 presents final-year medical students' knowledge and ability in completing the cause-of-death statement for the given case scenario. For I (a), the immediate cause of death, which was pulmonary embolism, 107 (61.5\%) answered correctly. The wrong answers mostly involved the use of abbreviations $(n=34 ; 19.5 \%)$ and the mention of the mechanism of death as cardiac arrest $(\mathrm{n}=$ $24 ; 13.8 \%)$. Other errors included the mention of an antecedent cause of death as the immediate cause of death $(\mathrm{n}=$ $5 ; 2.9 \%$ ) (eg, deep venous thrombosis), mention of clinical features $(\mathrm{n}=2 ; 1.1 \%)$ (eg, shortness of breath), and the mention of irrelevant causes of death $(\mathrm{n}=2 ; 1.1 \%)(\mathrm{eg}$,

Table 2 Students' Knowledge and Practice in Completing the Cause-of-Death Statement

\begin{tabular}{|c|c|c|}
\hline Cause of Death and Approximate Interval Between Onset and Death & Correct Answer & Wrong Answer \\
\hline I (a): Disease or condition directly leading to death & $107(61.5 \%)$ & $67(38.5 \%)$ \\
\hline Approximate interval between onset of I (a) and death & $99(56.9 \%)$ & $75(43.1 \%)$ \\
\hline I (b): Antecedent cause [morbid condition, if any, giving rise to the above cause, that is I (a)] & $124(71.3 \%)$ & $50(28.7 \%)$ \\
\hline Approximate interval between onset of I (b) and death & $118(67.8 \%)$ & $56(32.2 \%)$ \\
\hline I (c): Antecedent cause [morbid condition, if any, giving rise to the above cause, that is I (b)] & $20(11.5 \%)$ & $154(88.5 \%)$ \\
\hline Approximate interval between onset of I (c) and death & $18(10.3 \%)$ & $156(89.7 \%)$ \\
\hline I (d): Antecedent cause [morbid condition, if any, giving rise to the above cause, that is I (c)] & $167(96 \%)$ & $7(4 \%)$ \\
\hline Approximate interval between onset of I (d) and death & $167(96 \%)$ & $7(4 \%)$ \\
\hline II: Other significant conditions contributing to death & $15 \mid(86.8 \%)$ & $23(13.2 \%)$ \\
\hline Approximate interval between onset of II and death & 140 (80.5\%) & 34 (19.5\%) \\
\hline
\end{tabular}


pulmonary infarction, heart failure, and myocardial infarction). The correct time interval between the onset of the immediate cause of death and death was 5 hours. Of the students, $99(56.9 \%)$ answered this correctly. Wrong answers included the mention of 1 day and 1 hour. A blank space was also considered a wrong answer.

For I (b) antecedent cause of death, 124 (71.3\%) students answered deep venous thrombosis, the correct answer. However, the complete phrase "deep vein thrombosis of the left leg" was not mentioned by any of the students. The wrong answers included the mention of the immediate cause of death as the antecedent cause of death $(\mathrm{n}=31 ; 17.1 \%)$, mention of the underlying/contributor factors of cause of death $(\mathrm{n}=10 ; 5.7 \%)$, and the mention of clinical features $(n=4 ; 2.3 \%)$ (eg, shortness of breath). A blank space $(\mathrm{n}=5 ; 2.9 \%)$ was also considered as a wrong answer. The correct time interval between the onset of I (a) antecedent cause of death and death was 10 hours. This was answered correctly by 118 (67.8\%) students.

For I (c) antecedent cause of death, the underlying cause of death in the given case scenario, the correct answer Factor V Leiden thrombophilia, was answered by only $20(11.5 \%)$ students, whereas the remaining majority of the students wrongly left the corresponding space blank. The correct time interval between the onset of the underlying cause of death and death was written only by 18 $(10.3 \%)$ students.

The space provided for I (d) was correctly left blank by the majority of the students, and only 7 (4\%) wrongly mentioned bronchial asthma and the corresponding time interval of 15 years. The space provided for I (e) was correctly left blank by all the students.

For Part II, bronchial asthma was correctly answered as the other significant condition contributing to death by 151 (86.8\%) students and the corresponding time interval of 15 years was correctly provided by $140(80.5 \%)$ students.

Table 3 presents the responses of students to 10 independent statements/questions on the cause-of-death certification included in the questionnaire. Correct responses ranged from $28.7 \%$ to $79.9 \%$, with $70 \%$ of the questions being correctly answered by more than $50 \%$ of the students.

\section{Discussion}

The observations of the current study reflect the lacunae in the understanding of final-year medical students, the future doctors, in a Saudi Arabian university, on the cause-of- death certification and their ability to complete the causeof-death statement correctly in the given case scenario despite possessing reasonably good knowledge.

Data and information retrieved from the medical certificate of cause-of-death are used for national statistics, public health investigations, and allocating resources, and even for directing future research and healthcare programs. Errors in certification of the cause-of-death by doctors are well known. Therefore, it is important to begin training future doctors in writing death certificates during their years in the medical college itself.

Many doctors are not familiar with the drafting of death certificates or make errors when writing them. For instance, only $59 \%$ of UK doctors completed death certificates appropriately. ${ }^{14}$ Studies have shown more errors when residents or junior physicians fill out death certificates. ${ }^{15}$ Among the errors are listing the mechanism of death as the immediate cause of death, listing an unspecific or unacceptable cause of death (eg, sign or symptom), using abbreviations, including the wrong order of causes of death, and specifying the wrong underlying cause of death. ${ }^{15}$ These errors were also identified in the current study. Many factors can lead to cause-of-death certification errors and inappropriate filling out of death certificates by doctors, such as inexperience, lack of knowledge regarding the importance of death certificates, fatigue, time constraints, and responsibilities often falling on juniors in the team, with lack of feedback. ${ }^{16}$ One of the major causes is not receiving adequate training. Studies have reported that most physicians do not receive appropriate training. ${ }^{13}$

Studies have shown that simple educational interventions can minimize errors and improve the writing of cause-of-death certificates. ${ }^{17}$ In many medical colleges around the world cause-of-death certification is taught to medical students. ${ }^{17}$ However, there is no clear data being previously reported in the literature about the teaching of cause-of-death certification in the undergraduate medical curriculum in Saudi Arabia.

The results of the current study with regard to completing the cause-of-death statement are not entirely promising. Although $61.5 \%$ and $86.8 \%$ of the medical students wrote the immediate cause of death and other significant condition contributing to death correctly, respectively, only $11.5 \%$ wrote the underlying cause of death correctly. Not being able to decide the underlying cause of death in the given case scenario may suggest a lack of knowledge in hematology as the case scenario included to complete the cause-of-death statement in the current study was 
Table 3 Students Responses to 10 Independent Statements/Questions on the Cause-of-Death Certification

\begin{tabular}{|c|c|c|c|c|}
\hline The Statement & Agree & Disagree & $\begin{array}{l}\text { I Do Not } \\
\text { Know }\end{array}$ & $\begin{array}{l}\text { The } \\
\text { Correct } \\
\text { Answer }\end{array}$ \\
\hline $\begin{array}{l}\text { I. A physiotherapist/physical therapist involved in the care of the patient during his/her } \\
\text { final illness is entitled to fill the cause-of-death section of the death certificate/death } \\
\text { notification form. Do you agree with this statement? }\end{array}$ & 32 (I8.3\%) & III (63.9\%) & 31 (I7.8\%) & Disagree \\
\hline $\begin{array}{l}\text { 2. A pharmacist involved in the care of the patient during his/her final illness is entitled } \\
\text { to fill the cause-of-death section of the death certificate/death notification form. Do } \\
\text { you agree with this statement? }\end{array}$ & $13(7.5 \%)$ & II (67.2\%) & 44 (25.3\%) & Disagree \\
\hline $\begin{array}{l}\text { 3. A nurse involved in the care of the patient during his/her final illness is entitled to fill } \\
\text { the cause-of-death section of the death certificate/death notification form. Do you } \\
\text { agree with this statement? }\end{array}$ & 37 (21.2\%) & 99 (56.9\%) & 38 (21.9\%) & Disagree \\
\hline $\begin{array}{l}\text { 4. A doctor involved in the care of the patient during his/her final illness is entitled to } \\
\text { fill the cause-of-death section of the death certificate/death notification form. Do you } \\
\text { agree with this statement? }\end{array}$ & 139 (79.9\%) & $2(1.1 \%)$ & 33 (19\%) & Agree \\
\hline $\begin{array}{l}\text { 5. Cardiorespiratory arrest can be considered as an appropriate option for the } \\
\text { immediate cause of death. Do you agree with this statement? }\end{array}$ & 30 (I7.2\%) & 115 (66.1\%) & $29(16.7 \%)$ & Disagree \\
\hline $\begin{array}{l}\text { 6. Asphyxia can be considered as an appropriate option for the underlying cause of } \\
\text { death. Do you agree with this statement? }\end{array}$ & 30 (I7.2\%) & 119 (68.4\%) & 25 (14.4\%) & Disagree \\
\hline $\begin{array}{l}\text { 7. The immediate cause of death can be considered to be the underlying cause of } \\
\text { death in certain cases. Do you agree with this statement? }\end{array}$ & $102(58.6 \%)$ & $21(12.1 \%)$ & $5 I(29.3 \%)$ & Agree \\
\hline $\begin{array}{l}\text { 8. The underlying cause of death should always be an antecedent cause of death in } \\
\text { every death certificate. Do you agree with this statement? }\end{array}$ & $56(32.1 \%)$ & $50(28.7 \%)$ & 68 (39.2\%) & Disagree \\
\hline $\begin{array}{l}\text { 9. At least one antecedent cause of death should always be mentioned in every death } \\
\text { certificate. Do you agree with this statement? }\end{array}$ & 70 (40.2\%) & $63(36.2 \%)$ & $4 \mid(23.6 \%)$ & Disagree \\
\hline $\begin{array}{l}\text { 10. A contributory cause of death can be considered to be the underlying cause of } \\
\text { death in certain cases. Do you agree with this statement? }\end{array}$ & 61 (35.1\%) & 53 (30.4\%) & 60 (34.5\%) & Disagree \\
\hline
\end{tabular}

Note: ${ }^{\#}$ Considered as wrong answer.

a hematology case scenario with factor V Leiden thrombophilia as the underlying cause of death that began the chain of events leading to death. The inclusion of a different case scenario would have yielded different results. Nevertheless, correct responses to the immediate cause of death, antecedent cause of death [I (a)], and other significant contributory cause of death by $61.5 \%, 71.3 \%$, and $86.8 \%$ of the medical students, respectively, in the current study is an indication of their reasonably good knowledge in completing the cause-of-death statement. The correct responses for the corresponding time interval between a cause of death and death were $56.9 \%, 67.8 \%$, and $80.5 \%$, respectively, in the current study. Moreover, students fared well with their responses to the 10 independent statements/questions on the cause-of-death certification with $70 \%$ of the questions being correctly answered by more than $50 \%$ of the students.
Only $8 \%$ of the medical students wrongly wrote the mechanism of death as the immediate cause of death. The findings of the current study are better when compared to the physicians in Palestine, where only $48.7 \%$ filled out the immediate cause of death correctly, and $17 \%$ wrongly wrote the mechanism of death as the immediate cause of death. ${ }^{12}$

Errors in the current study typically included the use of abbreviations, mention of the mechanism of death as a cause of death, mention of clinical features as a cause of death, mention of irrelevant causes of death, and mention of the incorrect time interval between the onset of a cause of death and death. These errors were also reported in other studies where the participants were residents, specialists, and consultants. ${ }^{12,13}$

Many interventions can improve the accuracy of filling out death certificates. However, simple education and practical interventions might improve the accuracy more than threefold. This was proved by introducing a 90- 
minute seminar for residents, which led to dramatic improvement. Other means, such as offering self-learning material, peer auditing, using training videos, and publishing simplified uniform guidelines and forms, have been practiced. However, these methods were shown to be less effective than practical educational interventions. ${ }^{17,18}$ Most of the published data and interventions assessed residents and physicians, which is different from the current study that was aimed at medical students. Most of the medical students in the current study had participated in a tutorial on cause-of-death certification at the beginning of the first semester of the final year. Even if death certificate writing is taught theoretically, medical students lack opportunities in the practical education of completing death certificates during the clinical rotations, which is an important skill for future doctors.

\section{Limitations and Future Directions}

The current study has potential limitations. First and foremost, this cross-sectional study included only final-year medical students of a single medical college in Saudi Arabia. Therefore, the study findings cannot be generalized to the entire country and are obviously not applicable to diverse settings. Future studies should include students of more medical colleges in a country. Besides, since the medical curriculum differs in different countries, studies assessing comparisons among medical students of different countries should be considered in the future. Second, the current study was descriptive in design. Future studies should include the analytical component to assess any potential associated factors leading to the correct responses.

A third limitation concerns the selection of the case scenario to assess the ability of medical students to complete the cause-of-death statement. Only a single hematology case scenario was used in the current study. The responses to this single case scenario could be based on a multitude of factors including factors related to the medical curriculum, previous training, and timing of completing the questionnaire. More case scenarios are recommended to be included in such questionnaire surveys in the future. Besides, specifically, one case scenario each with a communicable disease, a non-communicable disease, and injury as the underlying cause of death is a recommendation being made to be considered in future studies.

Fourth, of the 10 independent statements/questions on the cause-of-death certification included in the questionnaire, a couple of them, namely, seventh and eighth, appear to have confused the participants of the study. Such confusing statements/questions should be excluded and instead, clear and concise statements/questions should be included while developing the questionnaire in future studies.

Further, pre- and post-educational intervention studies to assess the impact of formal education on medical students' knowledge and practice in cause-of-death certification are needed.

\section{Conclusion}

Completing a death certificate is an essential skill that all physicians should be well versed with. The current study found that the overall performance of final-year medical students was reasonably good except for the fact that most misunderstood the underlying cause of death in the given case scenario. The majority of the students had attended a tutorial on medical certification of cause-of-death during the first semester of the final-year before participating in the current study, which suggests that continuous training might be required.

\section{Ethical Approval}

This study was approved by the Institutional Review Board (IRB) of Imam Abdulrahman Bin Faisal University.

\section{Author Contributions}

The author made substantial contributions to conception and design of the study, acquisition of data, analysis, and interpretation of data; took part in drafting the article and revising it during the peer-review process; agreed to submit to the current journal; gave final approval of the version to be published; and agree to be accountable for all aspects of the work.

\section{Funding}

There is no funding to report.

\section{Disclosure}

None to be declared.

\section{References}

1. Twentieth world health assembly. Geneva: World Health Organization; 1967. Available from: https://apps.who.int/iris/handle/10665/85801. Accessed June 1, 2021.

2. International statistical classification of diseases and related health problems. 10th revision. Volume 2. Geneva: World Health Organization; 2011. Available from: https://www.who.int/classifica tions/icd/ICD10Volume2_en_2010.pdf. Accessed June 1, 2021.

3. Madadin M, Alhumam AS, Bushulaybi NA, et al. Common errors in writing the cause of death certificate in the Middle East. $J$ Forensic Leg Med. 2019;68:101864. 
4. Alipour J, Payandeh A. Common errors in reporting cause-of-death statement on death certificates: a systematic review and meta-analysis. J Forensic Leg Med. 2021;82:102220. doi:10.1016/j.jflm.2021.102220

5. Maharjan L, Shah A, Shrestha KB, Shrestha G. Errors in cause-ofdeath statement on death certificates in intensive care unit of Kathmandu, Nepal. BMC Health Serv Res. 2015;15:507. doi:10.1186/s12913-015-1168-6

6. Filippatos G, Andriopoulos P, Panoutsopoulos G, et al. The quality of death certification practice in Greece. Hippokratia. 2016;20:19-25.

7. Aljerian K. Death certificate errors in one Saudi Arabian hospital. Death Stud. 2019;43:311-315. doi:10.1080/07481187.2018.1461712

8. Gamage US, Adair T, Mikkelsen L, et al. The impact of errors in medical certification on the accuracy of the underlying cause of death. PLoS One. 2021;16:e0259667. doi:10.1371/journal.pone.0259667

9. MacDorman MF, Thoma M, Declercq E. Improving US maternal mortality reporting by analyzing literal text on death certificates, United States, 2016-2017. PLoS One. 2020;15:e0240701. doi:10.1371/journal.pone.0240701

10. Lakkireddy DR, Basarakodu KR, Vacek JL, et al. Improving death certificate completion: a trial of two training interventions. J Gen Intern Med. 2007;22:544-548. doi:10.1007/s11606-006-0071-6

11. Washirasaksiri C, Raksasagulwong P, Chouriyagune C, Phisalprapa P, Srivanichakorn W. Accuracy and the factors influencing the accuracy of death certificates completed by first-year general practitioners in Thailand. BMC Health Serv Res. 2018;18:478. doi:10.1186/s12913018-3289-1
12. Qaddumi JA, Nazzal Z, Yacoub A, Mansour M. Physicians' knowledge and practice on death certification in the North West Bank, Palestine: a cross sectional study. BMC Health Ser Res. 2018;18:8. doi:10.1186/s12913-017-2814-y

13. Al-Kubaisi NJ, Said H, Horeesh NA. Death certification practice in Qatar. Public Health. 2013;127:854-859. doi:10.1016/j.puhe.2012.12.016

14. Horner JS, Horner JW. Do doctors read forms? A one-year audit of medical certificates submitted to a crematorium. $J R$ Soc Med. 1998;91:371-376. doi:10.1177/014107689809100708

15. Lakkireddy DR, Gowda MS, Murray CW, Basarakodu KR, Vacek JL. Death certificate completion: how well are physicians trained and are cardiovascular causes overstated? Am J Med. 2004;117:492-498. doi:10.1016/j.amjmed.2004.04.018

16. Pandya H, Bose N, Shah R, Chaudhury N, Phatak A. Educational intervention to improve death certification at a teaching hospital. Natl Med J India. 2009;22:317-319.

17. Aung E, Rao C, Walker S. Teaching cause-of-death certification: lessons from international experience. Postgrad Med J. 2010;86:143-152. doi:10.1136/pgmj.2009.089821

18. Villar J, Perez-Mendez L. Evaluating an educational intervention to improve the accuracy of death certification among trainees from various specialties. BMC Health Serv Res. 2007;7:183. doi:10.1186/ 1472-6963-7-183
International Journal of General Medicine

\section{Publish your work in this journal}

The International Journal of General Medicine is an international, peer-reviewed open-access journal that focuses on general and internal medicine, pathogenesis, epidemiology, diagnosis, monitoring and treatment protocols. The journal is characterized by the rapid reporting of reviews, original research and clinical studies

\section{Dovepress}

across all disease areas. The manuscript management system is completely online and includes a very quick and fair peer-review system, which is all easy to use. Visit http://www.dovepress.com/ testimonials.php to read real quotes from published authors. 